\title{
Genetic deletion of mGlu2 metabotropic glutamate receptors improves the short- term outcome of cerebral transient focal ischemia
}

\author{
Federica Mastroiacovo', Slavianka Moyanova', Milena Cannella', Anderson Gaglione', Remy Verhaeghe',

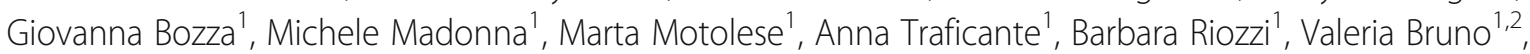 \\ Giuseppe Battaglia ${ }^{1}$, David Lodge ${ }^{3}$ and Ferdinando Nicoletti ${ }^{1,2^{*}}$
}

\begin{abstract}
We have recently shown that pharmacological blockade of mGlu2 metabotropic glutamate receptors protects vulnerable neurons in the 4-vessel occlusion model of transient global ischemia, whereas receptor activation amplifies neuronal death. This raised the possibility that endogenous activation of mGlu2 receptors contributes to the pathophysiology of ischemic neuronal damage. Here, we examined this possibility using two models of transient focal ischemia: (i) the monofilament model of middle cerebral artery occlusion (MCAO) in mice, and (ii) the model based on intracerebral infusion of endothelin-1 (Et-1) in rats. Following transient MCAO, mGlu2 receptor knockout mice showed a significant reduction in infarct volume and an improved short-term behavioural outcome, as assessed by a neurological disability scale and the "grip test". Following Et-1 infusion, Grm2 gene mutated Hannover Wistar rats lacking mGlu2 receptors did not show changes in the overall infarct volume as compared to their wild-type counterparts, although they showed a reduced infarct area in the agranular insular cortex. Interestingly, however, mGlu2 receptor-deficient rats performed better than wild-type rats in the adhesive tape test, in which these rats did not show the laterality preference typically observed after focal ischemia. These findings support the hypothesis that activation of mGlu2 receptors is detrimental in the post-ischemic phase, and support the use of mGlu2 receptor antagonists in the experimental treatment of brain ischemia.
\end{abstract}

Keywords: Focal ischemia, mGlu2 receptor, Genetic deletion, Neuroprotection, Neurological score

\section{Introduction}

Metabotropic glutamate (mGlu) receptors have been implicated in mechanisms of neurodegeneration/neuroprotection, and are promising drug targets for the treatment of acute and chronic neurodegenerative disorders [1]. It was believed for many years that group-II mGlu receptor agonists could produce neuroprotection by activating both mGlu2 and mGlu3 receptors [1], until it was shown in mouse primary cortical cultures that the protective activity of the mGlu2/3 receptor agonist, LY379268, against excitotoxic neuronal death was largely

\footnotetext{
* Correspondence: ferdinandonicoletti@hotmail.com

'IRCCS Neuromed, 86077 Pozzilli, Italy

${ }^{2}$ Department of Physiology and Pharmacology, Sapienza University of Rome, Piazzale Aldo Moro, 5, 00185 Rome, Italy

Full list of author information is available at the end of the article
}

mediated by the activation of glial mGlu3 receptors [2]. The unexpected findings that cultured neurons lacking mGlu2 receptors were more resistant to excitotoxic death and that systemic administration of LY379268 was protective against 1-methyl-4-phenyl-1,2,3,6-tetrahydropyridine neurotoxicity only in mGlu2 receptor knockout mice [2] raised the possibility that mGlu2 receptors facilitated neuronal death. This hypothesis was supported by a further in vitro study in which neurotoxicity caused by $\beta$ amyloid peptide was amplified by a selective positive allosteric modulator (PAM) of mGlu2 receptors, which was inactive when neurons lacked mGlu2 receptors [3]. The unexpected neurotoxic activity of mGlu2 receptors contributes to explain the contrasting data obtained with orthosteric mGlu2/3 receptor agonists in in vitro models of excitotoxic neuronal death [4-6], and the suboptimal 
effect of these drugs in animal models of global and focal brain ischemia [7-10].

Using the 4-vessel occlusion model of transient global ischemia, we found that post-ischemic systemic treatment with a selective negative allosteric modulator (NAM) of mGlu2 receptors protected vulnerable hippocampal CA1 pyramidal neurons, whereas treatment with a PAM of mGlu2 receptors extended the damage to resistant CA3 pyramidal neurons [12]. The possibility that mGlu2 receptor NAMs may be used as protective agents in brain ischemia is particularly promising because mGlu2 receptor NAMs are currently under preclinical and clinical development for the treatment of major depression, and show cognitive enhancing properties associated with a good profile of safety and tolerability [13]. However, transient global ischemia in rodents represents a model of brain hypoperfusion associated with cardiac arrest or hypotensive shock, but has no translational value for drug development in the treatment of stroke. It is therefore necessary to extend the study of mGlu2 receptors to models of transient focal ischemia that more closely mimic thromboembolic stroke in humans, such as the models of transient middle cerebral artery occlusion (MCAO) induced by filament insertion in mice [14] and intracerebral endothelin-1 (Et-1) infusion in rats [15]. We used these two models respectively in mGlu2 receptor knockout mice (mGlu2 $2^{-l-}$ ) and in Hannover Wistar rats (Han Wistar rats) $[16,17]$ lacking mGlu2 receptors to examine the influence of mGlu2 receptors on the short-term histological and behavioural outcome of transient focal ischemia.

\section{Results}

Infarct volume and improved behavioral outcome in mGlu2 receptor knockout mice subjected to transient MCAO

Transient MCAO in $\mathrm{mGlu}^{+/+}$mice caused a rapid development of ischemic infarct, which involved the striatum and a large proportion of the surrounding cerebral cortex. The ischemic infarct was detectable as early as $3 \mathrm{~h}$ after reperfusion, and reached its maximal size at 24-48 $\mathrm{h}$ after reperfusion (Fig. 1a). To examine whether MCAO could induce adaptive changes in the expression of mGlu2 receptors, we measured mGlu2 receptor protein levels by Western blot analysis in the cerebral cortex at $6 \mathrm{~h}$ after reperfusion. Measurements were performed in the core of the infarct area, in the neighboring cortical area, in the corresponding regions of the contralateral intact hemisphere, and in the corresponding regions of sham operated mice (see Fig. 1b). Western blot analysis showed a band at about $100 \mathrm{kDa}$ corresponding to mGlu2 receptor monomers, and a higher molecular size band, corresponding to receptor dimers. The identity of the two bands was confirmed using reference tissue from $\mathrm{mGlu} 2^{-/-}$mice (see immunoblot in Fig. 1c, d). mGlu2 receptor protein levels were not altered in the core region of the ischemic cerebral cortex as compared to the contralateral cortex or to the cortex of non-ischemic mice (Fig. 1c). In contrast, a slight but significant increase in mGlu2 receptor protein levels was seen in the cortical region neighboring the ischemic core as compared to the contralateral region and to the corresponding region of non-ischemic mice (Fig. 1d).

We next examined whether the lack of mGlu2 receptors could affect the extent of the ischemic lesion in mice subjected to transient MCAO induced by filament insertion into the external carotid artery. Macroscopic analysis of cerebrovascular anatomy did not show differences between $\mathrm{mGlu}^{-/-}$mice and their wild-type counterparts $\left(\mathrm{mGlu}^{+/+}\right)$. In addition, MCAO reduced regional cerebral blood flow (rCBF) to a similar extent in the two genotypes (Fig. 2a, b). The volume of ischemic infarct, evaluated by Nissl staining at $48 \mathrm{~h}$ after reperfusion, was significantly smaller in $\mathrm{mGlu}^{-/-}$mice, as compared to $\mathrm{mGlu}^{+/+}$mice (Fig. 2c, d).

In $\mathrm{mGlu}^{+/+}$mice, MCAO induced a neurological deficit with a score of about 2 (weakness and circling behavior towards the contralateral site) at 2 and $24 \mathrm{~h}$ after reperfusion. The deficit was attenuated at $48 \mathrm{~h}$. The neurological deficit was significantly reduced in $\mathrm{mGlu} 2^{-/-}$ at $24 \mathrm{~h}$ (Fig. 3a), but not at $48 \mathrm{~h}$ after ischemia.

The most striking difference between the two genotypes was observed when muscular strength of the left and right forelimbs was measured by the grip test. $\mathrm{mGlu}^{+/+}$mice showed a marked asymmetry in muscular strength, which was reduced in the contralateral forepaw at 2, 24, and $48 \mathrm{~h}$ after reperfusion. No asymmetry was found in mGlu2 ${ }^{-/-}$mice at any time point (Fig. 3b). The loss of muscular strength was significantly greater in $\mathrm{mGlu}^{+/+}$ mice than in mGlu2 $2^{-1-}$ mice at 2 and $24 \mathrm{~h}$ after reperfusion (Fig. 3b).

To exclude the possibility that $\mathrm{mGlu} 2^{-/-}$mice could be protected against ischemic damage because of compensatory changes in other mGlu receptor subtypes, we measured the transcripts of mGlu1, mGlu3, mGlu4, mGlu5, mGlu7, and mGlu8 receptors in the cerebral cortex and striatum of $\mathrm{mGlu}^{-/-}$mice and their wild-type littermates. We found no changes in the transcripts of the various mGlu receptor subtypes with the exception of the transcript of mGlu7 receptors, which was significantly reduced in the striatum of mGlu2 $2^{-1-}$ mice (Fig. 4).

\section{Short-term outcome of transient focal ischemia in wild-type and Grm2 mutant Han Wistar rats}

We could identify Han Wistar rats carrying a single point mutation of exon 3 of the Grm2 gene, which results into a stop codon at Cys407 and the lack of functional mGlu2 
a

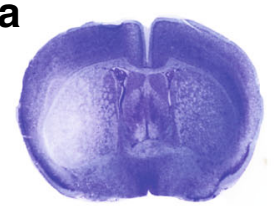

$\mathrm{MCAO}, 3 \mathrm{~h}$

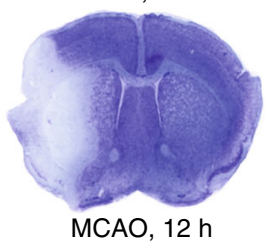

C

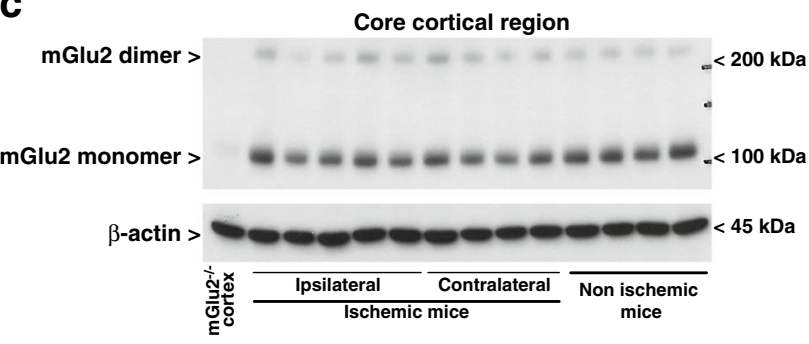

d

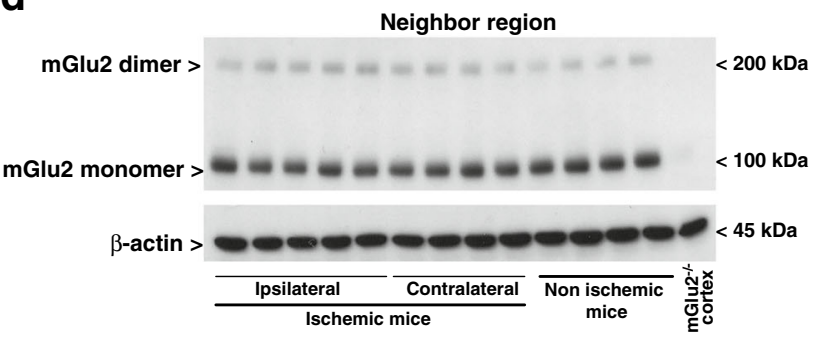

b
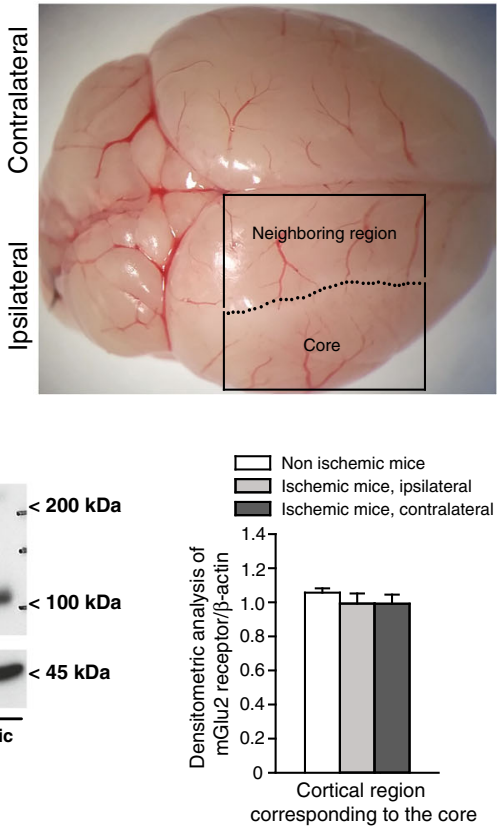

$\square$ Non ischemic mice $\square$ Ischemic mice, ipsilatera $\square$ Ischemic mice, contralateral

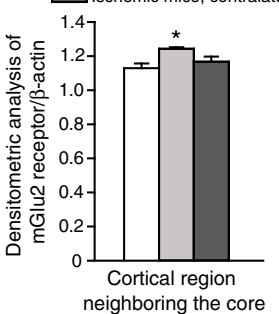

Fig. 1 mGlu2 Receptor protein levels in the cerebral cortex of $\mathrm{mGlu2}{ }^{+/+}$mice subjected to transient MCAO. Representative images of Nissl staining in coronal sections of mice at 3, 6, 12 and $48 \mathrm{~h}$ after monofilament-induced transient MCAO are shown in (a). The boundaries of dissection of the core region and the neighboring cortical region used for Western blot analysis are shown in (b). Immunoblot analysis of mGlu2 receptors in the cortical region corresponding to the core and in the cortical regions neighboring the core (and the corresponding regions of the contralateral hemispheres and of non-ischemic mice) is shown in (c) and (d), respectively. Densitometric data were obtained as the sum of the two bands corresponding to monomers and dimers. Data are means + S.E.M. of 4-5 mice per group. ${ }^{*} p<0.05$ as compared to all other groups (One-way ANOVA + Fisher's PLSD; $\left.F_{2,10}=9.26\right)$

receptors [17] (Fig. 5a). Wild-type (WT) and Grm2 mutant Han Wistar rats were subjected to transient focal ischemia induced by unilateral injection of Et-1 near the MCA of the left hemisphere (Fig. 5b). MCAO caused a large infarct volume detected after $72 \mathrm{~h}$, which did not differ between WT and Grm2 mutant rats (Fig. 5c, d). There was no difference in the infarct volume in the cerebral cortex and striatum between ischemic WT and Grm2 mutant Han Wistar rats, although a trend to a reduction in Grm2 mutant Han Wistar rats was observed (Fig. 5e, f). We also measured infarct area in different cortical subregions in a single section at $+0.2 \mathrm{~mm}$ from bregma, corresponding to the site of Et-1 injection (Fig. 6a). No significant differences in the infarct area between WT and Grm2 mutant rats were found in the forelimb region
(S1FL), dysgranular region (S1DZ), and upper lip region (S1ULp) of the primary somatosensory cortex and in the secondary somatosensory cortex (S2) (Fig. 6b, e). Grm2 mutant rats showed a significant reduction in the infarct area in the agranular insular cortex (AI) (Fig. 6g), and a trend to a reduction in the granular and dysgranular insular cortex (GI/DI) and claustrum (Cl) (Fig. 6f, h).

Behavioral assessment with a neurologic examination grading system that included a postural hang reflex test (PHR) showed a moderate to severe neurologic deficit in the right side of the body in both genotypes (Fig. 7a). Statistical analysis of asymmetry expressed by the laterality index revealed a significant effect of ischemia at all time sessions, as compared to pre-ischemic values $\left(\mathrm{T}_{0}\right)$, in both WT and Grm 2 mutant rats (Fig. 7a). 


\section{a}
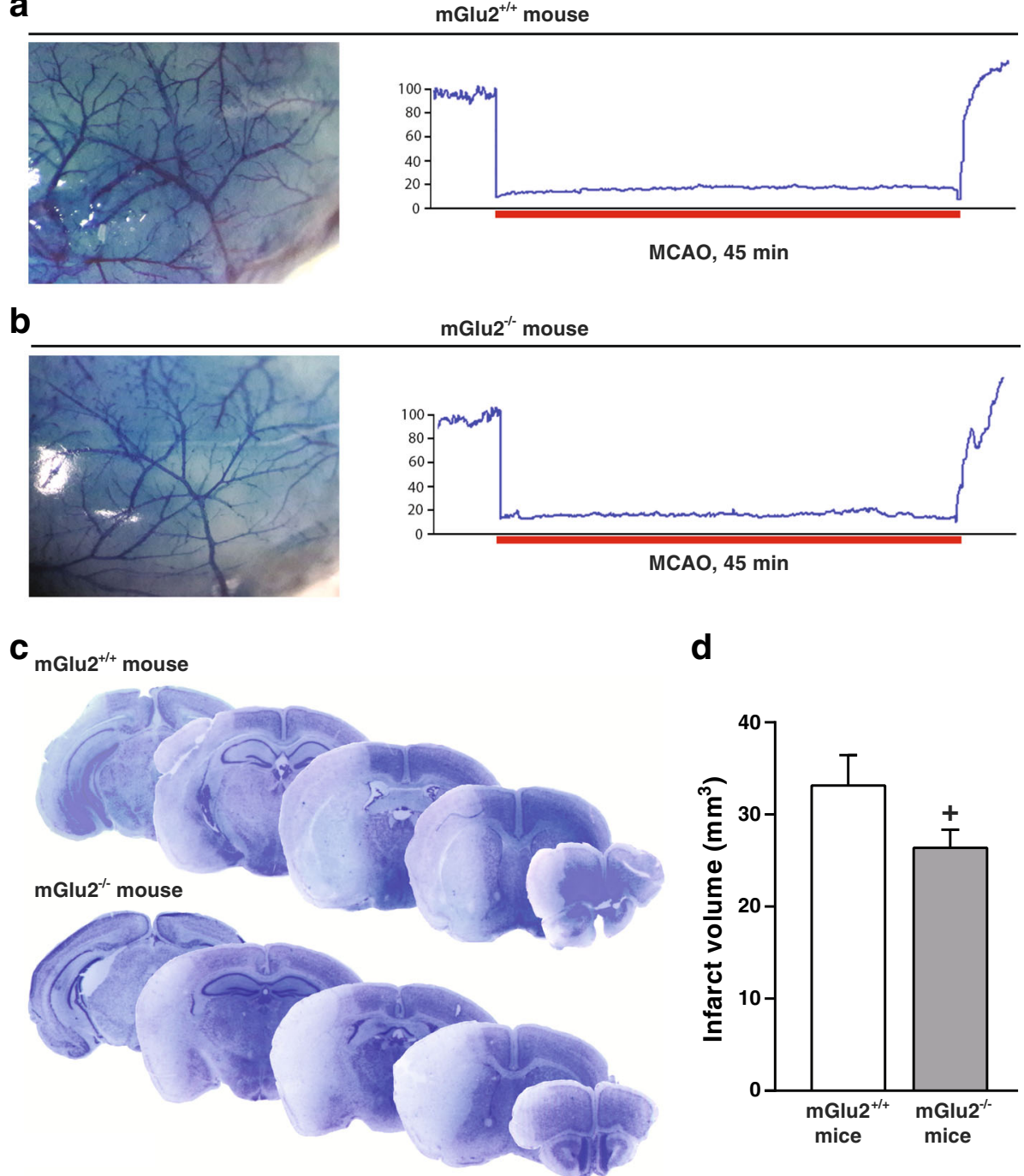

d

Fig. 2 Reduced infarct volume in $\mathrm{mGlu2}^{-/-}$mice subjected to transient MCAO. Evans blue perfusion showing the absence of anatomical abnormalities of the MCA mGlu2 $2^{-/-}$with respect to $\mathrm{mGlu2} 2^{+/+}$mice $(\mathbf{a}, \mathbf{b})$. No difference in the reduction of cerebral blood flow in response to MCAO was found among $\mathrm{mGlu2}^{+/+}$and $\mathrm{mGlu2} 2^{-/-}$mice. Nissl staining of $\mathrm{mGlu2}^{+/+}$and $\mathrm{mGlu2} 2^{-/-}$mouse brains after transient MCAO. Mice were killed $48 \mathrm{~h}$ after reperfusion (c). Values of infarct volume (d) are means \pm S.E.M. $\left(n=9\right.$ per group). ${ }^{+} p<0.05$ (Student's t-test; $\mathrm{t}_{16}=1.75$ )

A difference between the two strains of rats emerged from the analysis of preference and latency of removing the adhesive tapes in the adhesive tape test (AT) test, which is an active test of sensorimotor integration [18]. We found a large and significant increase in asymmetry in both parameters of the AT test (preference and latency) in WT rats at all times after Et-1 infusion $(1,24$, and $72 \mathrm{~h})$ (Fig. 7b, c). This was indicative of a severe defect in an active behavioral performance that requires sensorimotor integration [18]. Ischemia-induced asymmetry was much less severe in Grm2 mutant rats than in the WT rats. While the laterality index in the ischemic WT rats differed significantly from that in sham-operated WT rats, the laterality index in sham-operated and Et-1 infused Grm2 mutant rats was not significant different at all time points (Fig. 7b, c). There was a significant difference in laterality index between ischemic WT and Grm2 mutant rats at $72 \mathrm{~h}$ after Et-1 infusion (Fig. 7b, c).

\section{Discussion}

Neuroprotection remains an unmet need in the treatment of ischemic stroke. Disappointing data were obtained in clinical studies with ionotropic glutamate receptor antagonists in stroke owing to the strong impact of these drugs on fast excitatory synaptic transmission in the CNS, and the opposite role played by synaptic and extrasynaptic $\mathrm{N}$ methyl-D-aspartate (NMDA) receptors in neurodegeneration/neuroprotection [1-19]. In addition, NMDA receptor 


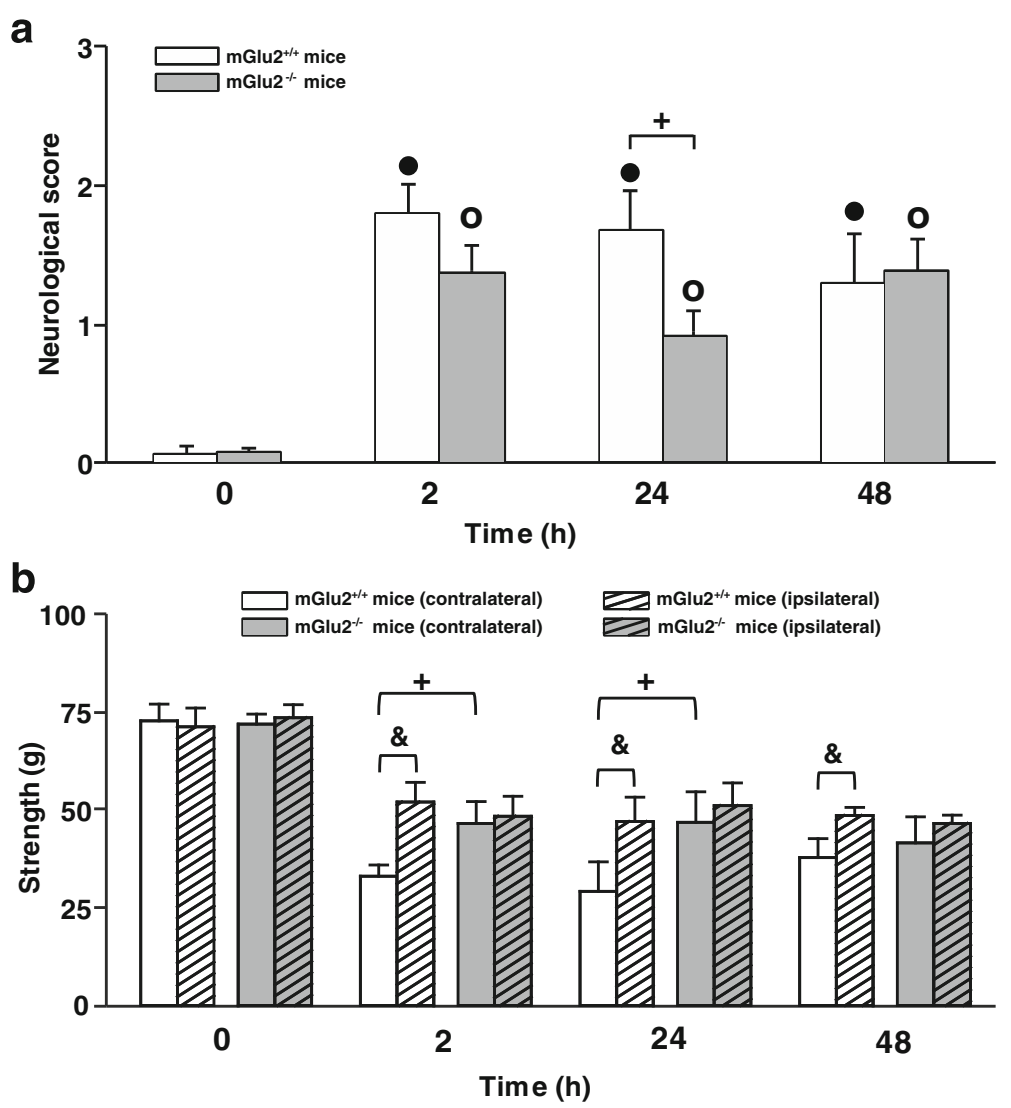

Fig. 3 Improved short-term behavioral outcome in mGlu2 $2^{-/-}$mice subjected to transient MCAO. Neurological deficit in $\mathrm{mGlu2} 2^{+/+}$and $\mathrm{mGlu2} 2^{-/-}$ mice subjected to transient MCAO (a). Bars are means + S.E.M. Friedman nonparametric ANOVA revealed significant effect of Time for mGlu2 ${ }^{+/+}$ mice [Chi Sqr. $(\mathrm{N}=7, \mathrm{df}=4)=23.46, p=0.0001]$ and for $\mathrm{mGlu}^{-/-}$mice [Chi Sqr. $\left.(\mathrm{N}=9, \mathrm{df}=4)=31.62, p=0.000001\right] ;(\bullet)$ and $(\mathrm{O})$ are Wilcoxon matched pairs comparisons between $T_{0}$ (before ischemia) and 2,24 and $48 \mathrm{~h}$ for mGlu2 ${ }^{+/+}$mice $(n=9)$ and mGlu2 ${ }^{-/-}$mice $(n=11)$, respectively; ${ }^{+}$ Kruskal-Wallis ANOVA and post-hoc Kruskal-Wallis test by ranks for difference between $\mathrm{mGlu2}{ }^{+/+}$and $\mathrm{mGlu2}^{-/-}$mice. Grip strength of ipsilateral and contralateral $\mathrm{FL}$ in $\mathrm{mGlu2}^{+/+}$and $\mathrm{mGlu2}^{-/-}$mice subjected to transient MCAO (b). MCAO resulted into a significant reduction in muscular strength in both, ipsilateral and contralateral FLs, after ischemia compared to $\mathrm{T}_{0}$ in $\mathrm{mGlu2}^{+/+}(n=7)$ and $\mathrm{mGlu2} 2^{-/-}$mice $(n=8)$ $\left(p<0.05\right.$, Dunnett's $t$ test). Three-way ANOVA for repeated measures (first factor GROUP with two levels: $\mathrm{mGlu2}^{+/+}$and mGlu2 ${ }^{-/-}$mice, second repeated measure factor SIDE with two levels: ipsilateral FL and contralateral FL, and third repeated measure factor TIME with four levels: $\mathrm{T}_{0}, 2,24$, and $48 \mathrm{~h}$ ) revealed significant effects of GROUP $\left(F_{1,9}=7.11, p=0.026\right)$, SIDE $\left(F_{1,9}=6.69, p=0.029\right)$, TIME $\left(F_{3,27}=21.16, p=0.0000001\right)$, interactions SIDE $x$ $\operatorname{TIME}\left(F_{3,27}=3.83, p=0.021\right)$ and GROUP $\times$ SIDE $\times$ TIME $\left(F_{3,27}=4.59, p=0.01\right)$. ${ }^{\&}$ Comparisons between ipsilateral and contralateral $\mathrm{FL}$ in $\mathrm{mGlu2}{ }^{+/+} \mathrm{mice}$ (Fisher LSD test). ${ }^{+}$Comparisons between $\mathrm{mGlu2}^{+/+}$and $\mathrm{mGlu2}^{-/-}$mice for the contralateral FL (Fisher LSD test)

antagonists impair mechanisms of activity-dependent synaptic plasticity and may cause severe adverse effects, such as psychotomimetic effects and intrinsic neurotoxicity [1]. mGlu receptor ligands modulate synaptic transmission, and are therefore considered as more valuable candidate targets for neuroprotective drugs. The mGlu receptor ligands developed so far for the treatment of CNS disorders have shown a good profile of safety and tolerability, which may reflect the modulatory role of mGlu receptors in synaptic transmission and activity-dependent synaptic plasticity.

Our interest in mGlu2 receptors as targets for neuroprotective drugs was raised by in vitro studies showing that the neuroprotective activity of $\mathrm{mGlu} 2 / 3$ receptor agonists against NMDA or $\beta$-amyloid toxicity was largely mediated by mGlu3 receptors, and that activation of mGlu2 receptors was instead neurotoxic [2, 3]. These findings laid the groundwork for an in vivo study in which we examined mGlu2 receptor expression in vulnerable and non-vulnerable hippocampal subregions and the effects of selective mGlu2 receptor ligands in the 4-vessel occlusion model of transient global ischemia. We found that mGlu2 receptor mRNA levels were lower in the resistant hippocampal CA3 region than in the vulnerable CA1 region, and that transient global ischemia selectively down-regulated mGlu2 receptors in the CA1 region [12]. In addition, we found that systemic post-ischemic treatment with a selective mGlu2 

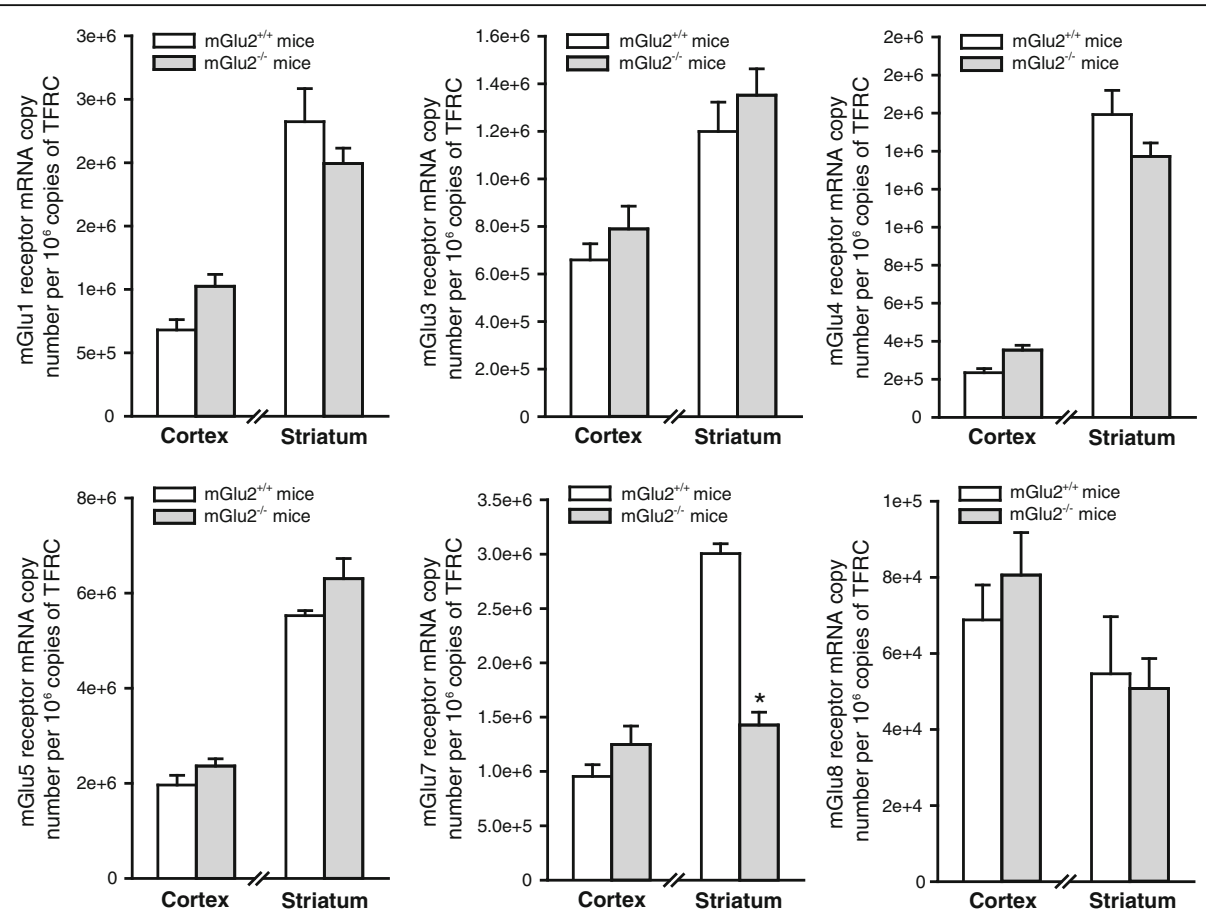

Fig. 4 Analysis of mGlu receptor subtypes in the cerebral cortex and striatum of $m G l u 2^{+/+}$and $m G l u 2^{-/-}$mice. Quantitative PCR analysis of mGlu1, mGlu3, mGlu4, mGlu5, mGlu7 and mGlu8 receptors mRNA levels in mGlu2 ${ }^{+/+}$and mGlu2 ${ }^{-1-}$ mice. mRNA values, expressed as copy number, were normalized to TFRC (transferrin receptor protein-1) and are means + S.E.M. of 4-8 mice per group. ${ }^{*} p<0.05$ (Student's $t$ test; $\mathrm{t}_{10}=4.59$ )

receptor NAM protected CA1 neurons against ischemic damage, whereas treatment with a selective mGlu2 receptor PAM extended the damage to CA3 neurons [12].

We have now studied the role of mGlu2 receptors in ischemic damage and the resulting behavioral impairment using two models of transient focal ischemia: (i) the monofilament model in mice; and, (ii) the Et-1 model in rats. In mice, transient MCAO did not induce early changes in the expression of mGlu2 receptors in a cortical area corresponding to the ischemic core, whereas it caused a significant increase in mGlu2 receptor protein levels in the neighboring cortical area that likely includes part of the penumbra region. This increase was small and its significance in the pathophysiology of ischemic damage is uncertain. However, these data further suggest that the ischemic insult causes adaptive changes in the expression of mGlu2 receptors.

Infarct size was significantly reduced in ischemic mGlu2 ${ }^{-/-}$mice as compared to their WT counterparts, but not in Grm2 mutant rats, although the extent of ischemic damage was similar in mice and rats following transient MCAO. The easiest explanation for this apparent discrepancy is that it is not the lack of mGlu2 receptors that protects $\mathrm{mGlu} 2^{-/-}$mice against damage caused by transient focal ischemia. Compensatory changes in the expression of other receptors or membrane transporters might render these mice less vulnerable to ischemic damage. It was logical to examine whether expression of other mGlu receptor subtypes was abnormal in the cerebral cortex and striatum of mGlu2 ${ }^{-/-}$mice. We found no changes in the transcripts of mGlu receptor subtypes that have been implicated in mechanisms of neurodegeneration/ neuroprotection, such as mGlu1, mGlu3, mGlu4, and mGlu5 receptors $[1,20,21]$. In contrast, the transcript of the mGlu7 receptors was substantially reduced in the striatum - but not in the cerebral cortex - of mGlu2 ${ }^{-/-}$ mice. We do not believe that this reduction contributes to reduce vulnerability of $\mathrm{mGlu} 2^{-1-}$ mice to ischemic damage because the mGlu7 receptor negatively modulates the activity of NMDA receptors [22], and, therefore, its activation is potentially neuroprotective. No need to say that possible alterations in other neurotransmitter receptors, membrane transporters or intracellular proteins might contribute to the reduced vulnerability of $\mathrm{mGlu}^{-/-}$mice to ischemic damage. This hypothesis warrants further investigation.

Interestingly, the absence of mGlu2 receptors improved the behavioral outcome of focal ischemia in both mice and rats. In $\mathrm{mGlu} 2^{-1-}$ mice neurological disability was significantly attenuated at $24 \mathrm{~h}$, but not at $48 \mathrm{~h}$ after ischemia, and the defect in the grip strength in the contralateral forearms was prevented in these mice at all time points after ischemia. Grm2 mutant rats lacking mGlu2 receptors showed a substantial improvement in their performance 
a

mGlu2 receptor protein (NP_001099181.1)

nt 1419 C > A

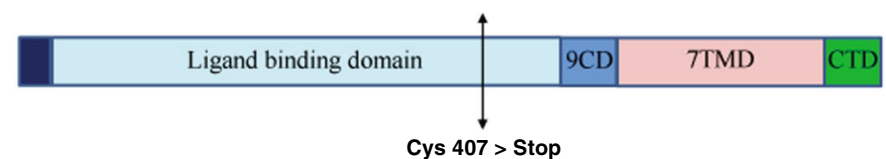

Wild-type

Mutant

$\frac{\text { Leu }}{C T C} \frac{\text { Cys }}{T G C} \frac{\text { Asp }}{G A T} \frac{\text { Ala }}{G C T}$

Leu STOP
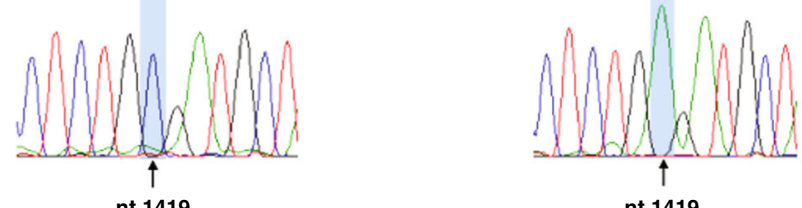

Grm2 wild-type (TGC) and mutant (TGA) chromatograms from Sanger sequencing

b

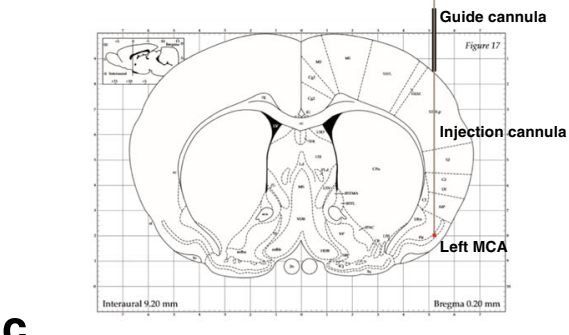

Sham-operated rat

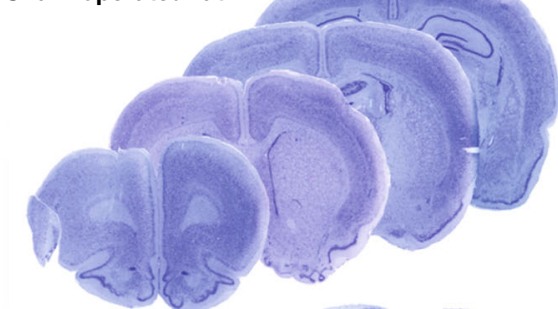

WT rat

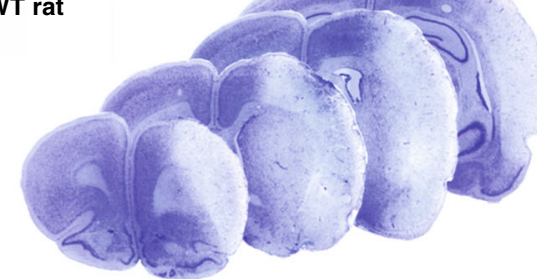

Grm2 mutant rat

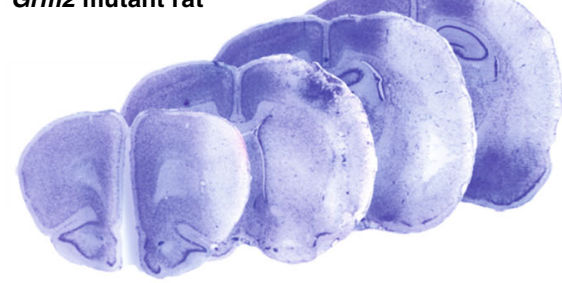

d
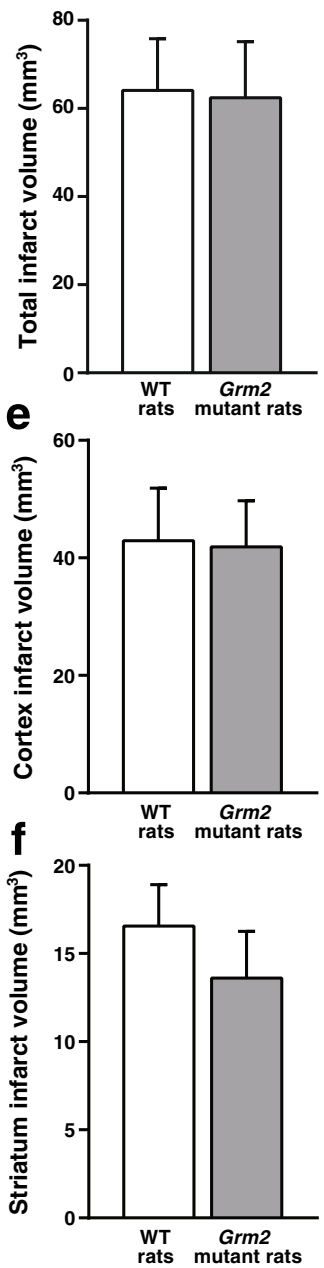

Fig. 5 (See legend on next page.) 
(See figure on previous page.)

Fig. 5 No difference in the infarct volume between WT and Grm2 mutant rats subjected to MCAO. WT and Grm2 mutant chromatograms from Sanger sequencing (a); scheme design of a coronal brain section at bregma level $+0.2 \mathrm{~mm}$ [30] (b); representative images of brain Nissl staining in non-ischemic (sham-operated rat), WT and Grm2 mutant Han Wistar rats subjected to transient MCAO (c); total infarct volume and infarct volumes in the cerebral cortex and striatum are shown in $(\mathbf{d}),(\mathbf{e})$, and $(\mathbf{f})$, respectively. Bars represent means + S.E.M. of 8 rats per group

in the AT test. This is an active test of sensorimotor integration involving the somatosensory cortex, anteromedial cortex, and striatum [23, 24]. The AT test, also called sensorimotor asymmetry test, models the tactile neglect in patients with frontal and parietal cortical lesions $[25,26]$. We were surprised to find that ischemic Grm2 mutant rats showed less asymmetry in the tape test as compared to WT rats, in spite of the similar extent of ischemic infarct in the two genotypes.
Ischemic Grm2 mutant rats showed a significant reduction of the infarct area in the dorsal portion of the AI, and a trend to a reduction in the granular and GI/DI and $\mathrm{Cl}$. The $\mathrm{Cl}$ is involved in the processing of sensorimotor and visuomotor information [27]. The dysgranular portion of the insular cortex receives projections from the secondary somatosensory area and, therefore, is also involved in somatosensory processing [28]. In contrast, the agranular portion of the insular cortex, which is part of the pain a
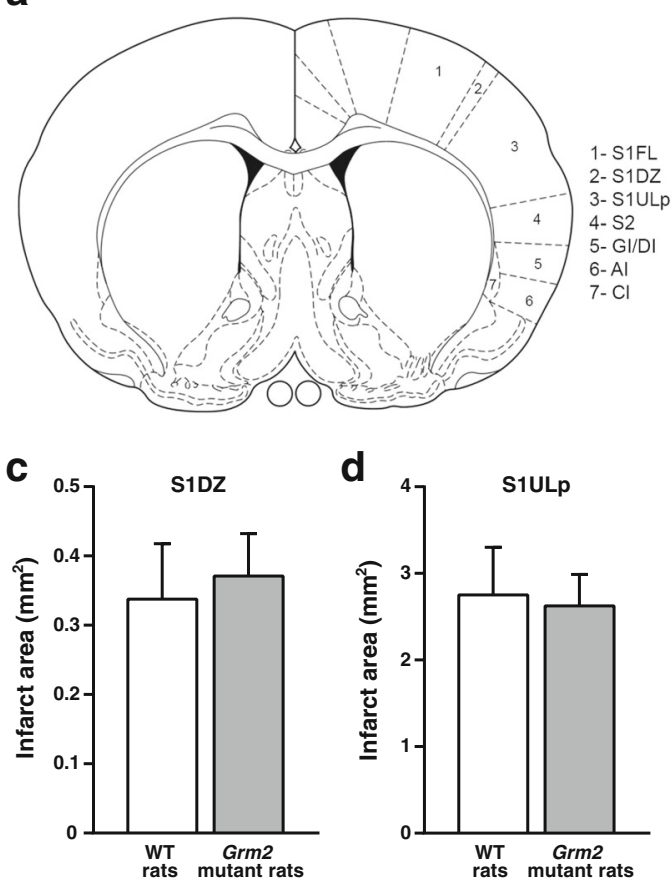

f

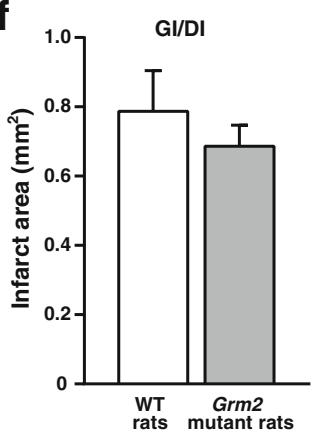

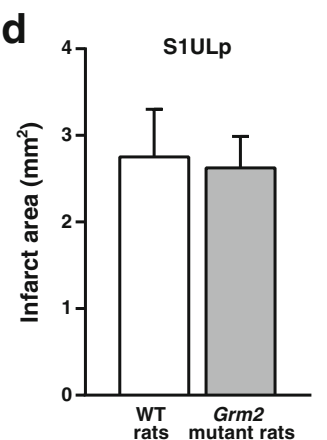

9

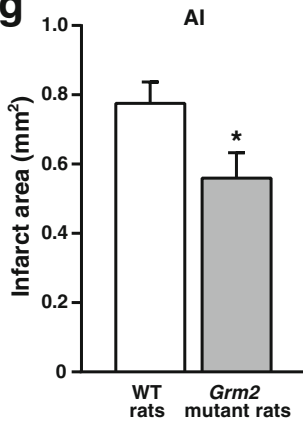

\section{b}
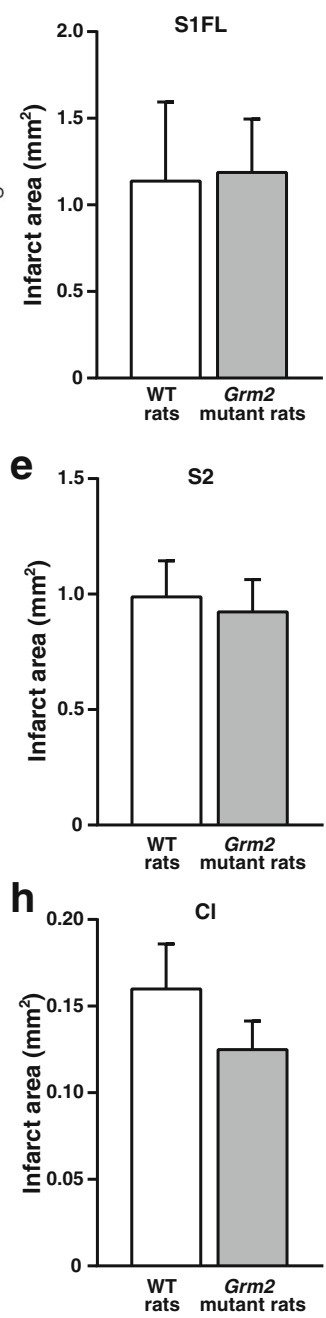

Fig. 6 Reduced infarct area in the agranular insular cortex of Grm2 mutant rats subjected to MCAO. Infarct areas of cortical sub-regions examined in one microscopic section (a) corresponding to the level of Et-1 infusion (AP $=+0.2 \mathrm{~mm}$ ) are shown in $(\mathbf{b}-\mathbf{h})$. Bars are means + S.E.M. of 8 rats per group. ${ }^{*} p<0.05$ (Student's t test). S1FL, S1DZ, and S1ULP = forelimb region, dysgranular region, and upper lip region of the primary somatosensory cortex, respectively; S2 = secondary somatosensory cortex; GI/DI, Al = granular/dysgranular, and agranular insular cortex, respectively; $\mathrm{Cl}=$ claustrum 


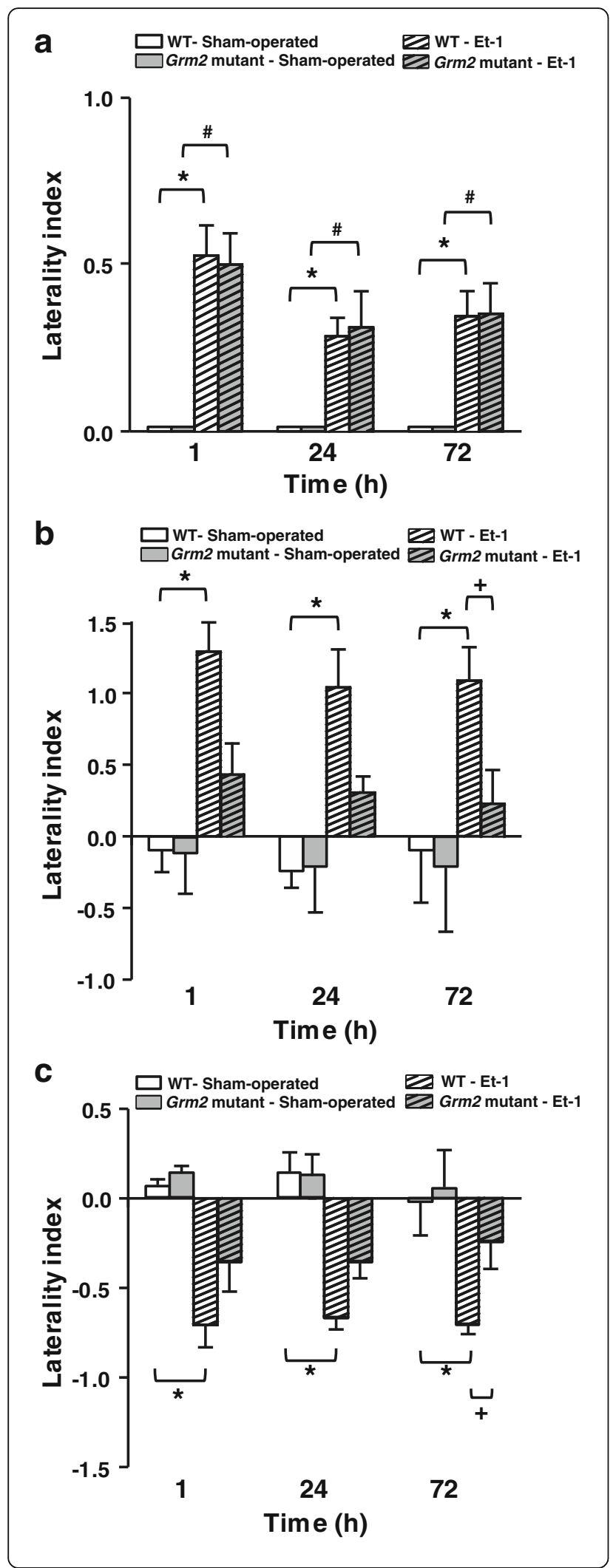

Fig. 7 Improved motor asymmetry in Grm2 mutant Han Wistar rats subjected to transient MCAO. Asymmetry (expressed by laterality index, normalized to pre-ischemia values) in the PHR test is shown in (a). Kruskal-Wallis nonparametric ANOVA and Mann-Whitney comparisons between Et-1-infused and sham-operated rats: ${ }^{*}$ ) for WT rats and (\#) Grm2 mutant rats, respectively; Asymmetry in the preference and latency of removing the adhesive tapes in the AT test is shown in (b) and (c), respectively. Three-way GLM rANOVA (first factor ISCHEMIA with two levels: Et-1 and sham-operated, second factor GROUP with two levels: WT and Grm2 mutant rats, and third factor TIME with three levels: 1, 24 and $72 \mathrm{~h}$ ) revealed a significant effect of factor ISCHEMIA for all rats, as follows: Preference $\left(F_{(1,15)}=12.84, p=0.003\right)$ and Latency $\left(F_{(1,15)}=28.31, p=0.00009\right)$. For ischemic rats (infused with Et-1), two-way rANOVA with factors GROUP (WT and Grm2 mutant rats) and TIME (1,24 and $72 \mathrm{~h}$ ) showed significant effect of the factor GROUP for both AT parameters, as follows: Preference $\left(F_{(1,10)}=10.84, p=0.008\right)$ and Latency $\left(F_{(1,10)}=10.83, p=0.008\right)$. * Fisher LSD comparisons between Et-1 and sham-operated WT rats and ${ }^{+}$between WT- Et-1 and Grm2 mutant-Et-1 rats. Number of rats: WT-sham-operated $(n=3)$; Grm2 mutant Han Wistar rats-sham-operated $(n=4)$; WT-Et-1 $(n=7)$; Grm2 mutant Han Wistar rats-Et-1 $(n=8)$. Significance was set at $p<0.05$

matrix, is involved in nociceptive processing [29], and may play a role in decision-making behavior under risk [30]. Of note, activation of the insular cortex is associated with orofacial movements [31], which are involved in sensorimotor integration during performance of adhesive tape removal. It is possible that in the post-ischemic period the application of a tape in the forepaw is processed as an aversive event and that activation of the $\mathrm{AI}$ is required for the decision to rapidly remove the tape. If so, the reduced infarct area in the AI might contribute to the better performance of mGlu2 $2^{-/-}$mice in the AT test. However, this is not fully convincing, and the combination of mouse and rat data suggest that, at least in models of focal ischemia, endogenous activation of mGlu2 receptors may not be critical for the development of ischemic neuronal damage, but becomes detrimental for functional recovery at short intervals after reperfusion. The use of selective mGlu2 receptor ligands will be a necessary step for an in-depth investigation of the role played by mGlu2 receptors in models of transient focal ischemia.

\section{Conclusions}

Our data suggest that endogenous activation of mGlu2 receptors is detrimental for the short-term outcome of transient focal ischemia, and support the hypothesis that pharmacological blockade of mGlu2 receptors is a valuable strategy for the treatment of brain ischemia. It is possible that endogenous activation of mGlu2 receptors contributes to dysfunction of synaptic plasticity and network activity underlying the imbalance between the two hemispheres in the early post ischemic phase, and that mGlu2 receptor antagonists correct this dysfunction thereby facilitating functional recovery. This is consistent with the "therapeutic" effect of mGlu2 receptor antagonists 
in experimental animal models of cognitive dysfunction associated with major depression [13].

The reduced infarct volume observed in $\mathrm{mGlu} 2^{-/-}$ mice subjected to transient focal ischemia leaves open the possibility that endogenous activation of mGlu2 receptors plays a permissive role in ischemic neuronal damage, although data obtained in Grm2 mutant rats are not consistent with this hypothesis. Further studies are needed to better understand the precise role played by mGlu2 receptors in the pathophysiology of ischemic neuronal death.

\section{Methods}

\section{Animals}

mGlu2 $2^{-/-}$mice on a $\mathrm{C} 57 \mathrm{Bl} / 6$ genetic background were kindly provided by Prof. Shigetada Nakanishi (Osaka, Japan) and the colony was generated by homozygous breeding. Han Wistar rats were purchased by Jackson Laboratories (Bar Harbor, ME) and genotyped for the presence of a stop codon mutation in the Grm2 gene (see below). All animals were housed under standard conditions with food and water ad libitum and a 12:12 h light-dark cycle. Studies were performed in agreement with the national and international guidelines and regulations on animal care and use, and were approved by the Neuromed Institutional Animal Care and Use Committee. All efforts were made to minimize animal suffering and to reduce the number of animals used.

\section{Induction of transient MCAO in mice}

\section{Surgery, stroke induction, inclusion criteria}

For measurements of mGlu2 receptor protein levels in the cerebral cortex at $6 \mathrm{~h}$ following ischemia, we used 4 nonischemic and 5 ischemic C57Bl mice (20-25 g, b.w.). For the study of focal ischemia in mice lacking mGlu2 receptors we used 15 male mGlu2 $2^{-/-}$mice and 11 age-matched male $\mathrm{mGlu}^{+/+}$mice (20-25 g, b.w.). Transient MCAO occlusion was induced as described by Nygren and Wieloch [14]. Briefly, anesthesia was induced by inhalation of $2.5 \%$ isoflurane in $\mathrm{N}_{2} \mathrm{O} / \mathrm{O}_{2}$ (70:30) and maintained at $2 \%$ by a face mask during the initial phase of surgery. Body temperature was maintained at $37{ }^{\circ} \mathrm{C}$ using a heating pad and controlled by a device connected with a temperature probe inserted into the rectum. rCBF was monitored by a flexible optical fiber connected to a laser Doppler (PeriFlux System 5000; Perimed, Jarfalla, Sweden) mounted on the skull in correspondence of the MCA of the right hemisphere. A silicon-coated filament (6-0 MCAO suture, Doccol Corporation, Sharon MA) was introduced into the internal carotid artery through an incision in the external carotid artery. The filament was advanced until it blocked the origin of the right MCA. Filament placement was confirmed by a reduction in laser Doppler flow and then, the isoflurane concentration was decreased to $1.5 \%$ during the MCA occlusion (45 min). We have included into analysis only mice with adequate occlusion, as determined by (1) rCBF reduction by at least $70 \%$ immediately after filament placement; (2) sustained reduction of rCBF for 45 min during occlusion; and, (3) complete recovery of rCBF within $5 \mathrm{~min}$ after the filament was removed. Therefore, $9 \mathrm{mGlu} 2^{+/+}$and $9 \mathrm{mGlu} 2^{-/-}$mice were included in statistical analysis for evaluation of the infarct volume. Nine $\mathrm{mGlu} 2^{+/+}$and $11 \mathrm{mGlu} 2^{-/-}$mice were included in statistical analysis for evaluation of neurological deficits. Two $\mathrm{mGlu}^{-/-}$mice died before performing the last behavioural test and therefore were not included in the infarct volume analysis. Seven $\mathrm{mGlu}^{+/+}$and $8 \mathrm{mGlu}^{-/-}$ mice were used for statistical analysis of the grip strength test. After surgery, mice were injected with $0.5 \mathrm{ml}$ of $5 \%$ glucose subcutaneously, placed into an incubator (Compact incubator, Thermo Scientific, AHSI, Bernareggio (MI), Italy) at $37 \mathrm{C}^{\circ}$ for $2 \mathrm{~h}$, and then returned back to their home cages. Animals were killed $48 \mathrm{~h}$ after MCAO and their brains processed for histologic analysis.

\section{Western blot analysis of mGlu2 receptors following transient focal ischemia}

Ischemic mice were killed by decapitation $6 \mathrm{~h}$ following reperfusion. A cortical area corresponding to the ischemic core (identified by the presence of a white boundary from the surrounding tissue) and the neighboring cortical area (see Fig. 1b) were dissected. The corresponding regions of the contralateral hemispheres and the corresponding regions of the cerebral cortex of sham-operated mice were also dissected and stored frozen at $-80{ }^{\circ} \mathrm{C}$. Samples homogenized at $4{ }^{\circ} \mathrm{C}$ in in a solution containing Tris- $\mathrm{HCl}$ ( $\mathrm{pH} 7.5), \mathrm{NaCl}(50 \mathrm{mM})$, EDTA $(5 \mathrm{mM})$, and an Ultra Cruz Protease Inhibitor cocktail. Ten $\mu \mathrm{g}$ of proteins from the supernatants were separated by $8 \%$ SDS polyacrilamide gel. Proteins were transferred on immuno-blot PVDF membranes (Trans-Blot Turbo Transfer Systems, Bio-Rad, Segrate, MI, Italy), which were incubated with a polyclonal anti-mGlu2 receptor antibody (Abcam, Cambridge, UK; 1:1000 in t-TBS) for $1 \mathrm{~h}$ at room temperature, and then incubated for 1 more $h$ with an anti-mouse secondary antibody (Calbiochem, San Diego, CA; 1:7000 in tTBS). For $\beta$-actin immunostaining, membranes were incubated with a mouse monoclonal antibody (Sigma-Aldrich, St Louis, MO; 1:50,000) in milk 5\%, for $1 \mathrm{~h}$ at room temperature, and then incubated for 1 more $\mathrm{h}$ with an anti-mouse secondary antibody (Calbiochem; 1:7000 in tTBS). Immunostaining was revealed by the enhanced ECL western blotting analysis system.

\section{Behavioral tests}

Evaluation of neurological function

We assessed the neurological function $1 \mathrm{~d}$ before $\left(\mathrm{T}_{0}\right)$ and at 2, 24, and $48 \mathrm{~h}$ after MCAO. Neurological function was 
scored by an investigator who was unaware of the genotype. We used the following grading system: $0=$ no deficit; 1 = forelimb weakness; 2 = circling toward the affected, contralateral (left) side; 3 = partial paralysis of the affected side; $4=$ no spontaneous motor activity [32].

\section{Grip strength test}

We assessed neuromuscular function by using the Grip strength meter (2 Biological Instruments, Besozzo, VA, Italy). The mouse voluntarily gripped a bar with either the healthy (ipsilateral) or the affected (contralateral) forelimb (FL) and pulled it backward. A mean of five trials was used for analysis. We assessed muscular strength one day before ischemia $\left(\mathrm{T}_{0}\right)$ and then, at 2,24 , and $48 \mathrm{~h}$ after MCAO.

Quantitative analysis of the transcripts of mGlu1, $-3,-4$, $-5,-7$, and -8 receptors in the cerebral cortex and corpus striatum of non-ischemic $\mathrm{mGlu}^{+/+}$and $\mathrm{mGlu} 2^{-/-}$ mice

Mice were killed by decapitation and the brain was quickly removed; a cortical area corresponding to both dissected regions in Fig. 1b, and the striatum were dissected on ice and immediately frozen on liquid nitrogen, and stored at $-80{ }^{\circ} \mathrm{C}$. Total RNA was extracted using Trizol reagent (Thermo Fisher Scientific, Waltham, MA) according to manufacturer's protocol. The RNA was then treated with DNAse (Qiagen, Hilden, Germany) and single strand cDNA was synthesized from $2 \mu \mathrm{g}$ of total RNA using superscript III (Thermo Fisher Scientific) and random hexamers. Real-time PCR was performed as described previously [12]. The following primers were used: mGlu1 receptor, forward CATACGGAAAGGGGAAGT GA and reverse AAAAGGCGATGGCTATGATG; mGlu3 receptor, forward CAGCAAGCTCCCTCTTTTGT and Rev. GCTAAAAGAGCCCGTCACTG; mGlu4 receptor, forward CTCCAGCCGCACGCTTGACA and reverse GTAGGCCGAGTCCTGCCCGA; mGlu5 receptor, forward ACGAAGACCAACCGTATTGC and reverse AGA CTTCTCGGATGCTTGGA; mGlu7 receptor forward GG TTTTCGTCAAGCCAGAGA and reverse ATCACTGA GTTCAGGAGCCG; mGlu8 receptor forward CGGAATC TGAACTTGCTCGG and reverse GGGGGAAGGCTT TAGGGATTT; and TFRC (transferrin receptor protein-1) forward CCAGTGTGGGAACAGGTCTT and reverse GC ACCAACAGCTCCAAAGTC.

DNA extraction, PCR amplification and sanger sequencing method for Han Wistar genotyping

DNA was extracted from the tail using Wizard genomic DNA purification kit (Promega Corporation, Madison, WI) according to manufacturer's protocol. Fifty $\mu \mathrm{g}$ of DNA was used for PCR amplification with following primers forward: - 5' GAACAGGAGTCAAAGATCATG 3' and reverse: -
5' CAGCACTATTACCGTCAAAC 3'. Thermal cycler conditions were as follows: $10 \mathrm{~min}$ at $95^{\circ} \mathrm{C}, 35$ cycles of denaturation $\left(30 \mathrm{~s}\right.$ at $\left.95^{\circ} \mathrm{C}\right)$, annealing $\left(30 \mathrm{~s}\right.$ at $\left.55^{\circ}\right)$ and extension $\left(45 \mathrm{~s}\right.$ at $\left.72{ }^{\circ} \mathrm{C}\right)$; the extension was continued at $72{ }^{\circ} \mathrm{C}$ for $7 \mathrm{~min}$. Five $\mu \mathrm{m}$ of amplificated DNA was separated in a $2 \%$ agarose gel. All positive PCR products were purified by Minielute PCR purification kit (Qiagen) by standard procedures and 5 ng were sequenced with Big Dye Terminator v. 3.3 mix (Thermo Fisher Scientific) with forward primer by using the following thermal cycler conditions program: 30 cycles of denaturation $\left(10 \mathrm{~s}\right.$ at $\left.95^{\circ}\right)$ annealing $\left(5 \mathrm{~s}\right.$ at $\left.54^{\circ}\right)$ and extension $\left(4 \mathrm{~min} 60^{\circ}\right)$. Excess dye terminators were removed using 2.0 spin kit (Qiagen); samples were electrophoresed on an ABI Prism 310 genetic analyzer (Applied Biosystems, Foster City, CA) for genotype analysis.

\section{Et-1-induced focal ischemia in mutant Han Wistar rats Surgery, stroke induction, inclusion criteria}

Twenty-six rats (weight $310 \pm 40$ g) were used: 13 Grm2 mutant Han Wistar and 13 WT. We used the Et-1 model of ischemia for the induction of transient focal ischemia. Rats were anaesthetized with an intramuscular injection of a mix of ketamine $(60 \mathrm{mg} / \mathrm{kg})$ and xylazine $(12 \mathrm{mg} / \mathrm{kg})$ dissolved into saline. A guide cannula was placed at the following stereotaxic coordinates: $\mathrm{AP}+0.2$; $\mathrm{ML}+5.2$ [33] avoiding to damage the dura mater. A stainless steel wire was insert into the guide cannula to plug it until the day of the Et-1 infusion. The guide cannula was secured to the skull with two supporting screws and dental cement. We infused Et-1 (200 pmol in $3 \mu \mathrm{l}$ of saline) $15-16 \mathrm{~d}$ after the surgery (a 5 days-treatment with Baytril antibiotic, $0.2 \mathrm{ml} / \mathrm{kg}$, s.c., $3 \mathrm{~d}$ of handling, $5 \mathrm{~d}$ of habituation to the experimental room and experimental cage and training in the AT test, and $3 \mathrm{~d}$ for control sessions before the Et-1 infusion). Et-1 was infused in non-anesthetized rats by inserting an injection cannula into the guide cannula. The tip of the injection cannula targeted the piriform cortex approximately $0.2 \mathrm{~mm}$ from the MCA origin in the left hemisphere. The same procedure was carried out in sham-operated rats, infused with vehicle. We assessed the ischemiainduced neurological deficits 10-15 min after Et-1 infusion using the following 7-point scale: $0=$ normal; 1 = held to face the table edge (to avoid vibrissae and snout contacts with the table, the rat chin was supported upward), the rat failed to place its right FL on the table when we pushed the limb down with a soft bar (failed proprioceptive dorsal FL placing); 2 = held and slightly pushed to face the table edge from inside, the rat failed to hold its FL on the edge of the table and slipped off (failed proprioceptive ventral FL placing); 3 = suspended by the tail, the rat twisted the torso upward; $4=$ suspended by the tail, the rat failed to extend the right FL down, and the limb was flexed and/or clenched; $5=$ after 
being placed on the table, the rat turned its body to the right (spasmodic turning); $6=$ the rat circled continuously to the right after being placed on the table. Ischemia was considered as severe with scores from 11 to 21, moderate, from 3 to 10; slight from 1 to 2 . Twenty-two rats (10 WT and 12 Grm2 Han Wistar mutant) satisfied these inclusion criteria.

\section{Behavioural tests \\ Neurological assessment and PHR test}

We assessed spontaneous activity, symmetry in limb movement, forepaw outstretching, and resistance to lateral push and circling behavior [34]. In detail, we assessed: (i) flexion and/or clenching of the digits and/ or full flexion of the wrist when the rat was suspended by the tail (PHR test); (ii) asymmetry in resistance to applied lateral gentle pressure from behind the shoulders in the left and right directions (the rat was placed on a flat surface). Ischemic rats showed less resistance of the right part of the body (contralateral to the ischemic hemisphere). The right FL became stiff during the push, while the left FL offered resistance; (iii) body twisting when the rat was suspended by the tail (PHR test); and, (iv) circling or inability to walk straight when the rat was placed on a flat surface. The following 4score grading system was adopted: $0=$ impairment in (i), (ii), (iii), and (iv) (severe motor deficit); 1 = impairment in (i), (ii), and (iii) (moderate motor deficit); 2 = impairment in (i) and (ii) (mild motor deficit); $3=$ no deficit.

\section{AT test}

Two adhesive tapes $(1 \times 1 \mathrm{~cm})$ were placed on the radial aspect of both FLs alternating the order of their application, i.e., right versus left. Both ATs were then pressed slightly and simultaneously and rats were placed immediately within a box and the time in seconds (precision of measuring $1.0 \mathrm{~s}$ ) needed to remove the ATs (latency) and the order (preference) of FLs (left or right) for removing the first AT was recorded. Rats were pre-trained (five trials for five successive days) to obtain optimal level of performance (latency $\leq 28 \mathrm{~s}$ ) and to achieve absence of asymmetry between right and left FL performance before stroke induction. The experimenter was blind to the rat group (Et-1, sham-operated, WT or Grm2 mutant). A trial ended when three min had elapsed without removing of either of the two ATs. For the preference, the ipsilateral (Ipsi) and contralateral (Contra) values referred to mean percentage of trials (out of five for each pre- or post-Et-1 session) in which the rat removed the AT placed on the left or right FL, respectively. For the latency, the Ipsi and Contra values referred to mean time (for five trials in each pre- or
post-Et-1 session) needed to remove the AT from the ipsilateral or contralateral FL, respectively.

\section{Asymmetry assessment in behavioural performance (AT and PHR tests)}

The asymmetry in behavioural performance was assessed by means of the Laterality Index (LI) $=$ (Ipsi - Contra) / (Ipsi + Contra). For the PHR test, the range of LI was between 0 (normal PHR, equal scores for the right and left sides of the body) and +1.0 (maximum ischemic deficit, PHR score for the right, contralateral side was 0 ). For the preference in the AT test, having in mind that the range of the preference was between $0 \%$ and $100 \%$, the range of LI was from +1.0 (full ipsilateral preference or maximum ischemic deficit) through 0.0 (normal performance) to - 1.0 (full contralateral preference). For the latency in the AT test, having in mind that the range of the latency was between $1.0 \mathrm{~s}$ and (equal to the precision of measuring) $180.0 \mathrm{~s}$, the range of LI was from approximately +1.00 (fast contralateral response and lack of ipsilateral response) through 0.00 (equal responses of both FLs, normal), to approximately -1.00 (fast ipsilateral response and lack of contralateral response, maximum ischemic deficit). The time sessions were $T_{0}, 1$, 24, $72 \mathrm{~h}$, where $\mathrm{T}_{0}$ was mean value of LIs of Preference or Latency before the Et-1 (or Saline) infusion on three consecutive days, with five trials on each day. The values of laterality index were normalized by subtracting the control values (at $\mathrm{T}_{0}$ ).

\section{Histological analysis}

Mice and rats were sacrificed respectively at 48 and $72 \mathrm{~h}$ post MCAO and brains were fixed in Carnoy's solution, embedded in paraffin, and sectioned at $10 \mu \mathrm{m}$. Sections regularly spaced every $550 \mu \mathrm{m}$ (through the extension of the ischemic region) were deparaffinized and processed for staining with thionin (Nissl staining for histological assessment of neuronal degeneration). The infarct area was outlined at magnification of X 2.5 and measured with Scion Image software (NIH, Bethesda, MD, USA), then the infarct volume $(\mathrm{V})$ was calculated by integrating the crosssectional area of damage on each level and the distance between them: $V=\Sigma\left(A_{i} \times T_{S \_} \times n\right)$, where $A_{i}$ is the ischemic area measured at $\mathrm{i}$-th section, the $\mathrm{T}_{\mathrm{S}}$ is the section thickness $(10 \mu \mathrm{m})$, and $\mathrm{n}$ is the number of sections between two adjacent levels. In addition, we measured in rats the infarct area at level of a single section $(\mathrm{AP}=+0.2 \mathrm{~mm}$ from bregma) in the S1FL, S1DZ, S1ULp, S2, GI/DI, AI and Cl.

\section{Statistics}

For the neurological test in mice and the PHR test in rats, we used Kruskal-Wallis nonparametric ANOVA for multiple unrelated samples (Statistical package Statistica 7.0, 2004, Statsoft, Tulsa, OK) to determine the overall 
group effect at each time point. Then Mann-Whitney Utest (corrected for the small size of independent samples) was performed for the evaluation of the differences between Et-1 and sham-operated rats, separately for WT and Grm2 mutant rats. Friedman ANOVA by ranks and subsequent Wilcoxon matched-pairs test for related samples were used for evaluation of changes in neurological scores in mice and asymmetry in the PHR test in rats as a function of time.

Statistical analysis of the grip strength test in mice and asymmetry in the AT test in rats was performed by threeway repeated measures Hotelling ANOVA (General Linear Model, Statistica7.0, Statsoft) with factors: Group $\left(\mathrm{mGlu}_{2}{ }^{+/}, \mathrm{mGlu}^{-/-}\right.$), Side (Ipsilateral FL, Contralateral FL) and Time ( $\mathrm{T}_{0}, 2,24$ and $\left.48 \mathrm{~h}\right)$ in mice, and two-way repeated measures Hotelling ANOVA for asymmetry in AT preference and latency with factors: - Group (WT, Grm 2 mutant) and Time ( $\mathrm{T}_{0}, 1,24$ and $72 \mathrm{~h}$ ) in rats. For Post-hoc analysis we used Fisher's LSD or Dunnett's tests. Student's' $t$ test was used for the analysis of infarct volumes in mice and rats (Statistica 7.0, Statsoft).

\section{Acknowledgements}

Not applicable.

\section{Availability of data and materials}

The datasets generated during and/or analyzed during the current study are available from the corresponding author on reasonable request.

\section{Funding}

No specific funding was received.

\section{Authors' contributions}

FM and SM designed and performed histological and behavioral analysis, analyzed the data and wrote the manuscript; MC, MiM, MaM and AT generated mouse and rat colonies and performed genotype analysis; BR performed Western blotting analysis; AG, RV and GB performed behavioral analysis; VB and GB analyzed the data and revised the manuscript; DL and FN designed experiments and wrote the manuscript. All authors read and approved the final manuscript.

\section{Ethics approval and consent to participate}

Studies involving animals were performed in agreement with the National and International guidelines and regulations on animal care and use, and were approved by the Neuromed Institutional Animal Care and Use Committee. All efforts were made to minimize animal suffering and to reduce the number of animals used.

\section{Consent for publication}

Not applicable.

\section{Competing interests}

The author(s) declared no potential conflicts of interest with respect to the research, authorship, and/or publication of this article.

\section{Publisher's Note}

Springer Nature remains neutral with regard to jurisdictional claims in published maps and institutional affiliations.

\section{Author details}

${ }^{1}$ IRCCS Neuromed, 86077 Pozzilli, Italy. ${ }^{2}$ Department of Physiology and Pharmacology, Sapienza University of Rome, Piazzale Aldo Moro, 5, 00185 Rome, Italy. ${ }^{3}$ School of Physiology, Pharmacology and Neuroscience, University of Bristol, Bristol BS8 1TD, UK.
Received: 27 April 2017 Accepted: 9 August 2017

Published online: 18 August 2017

\section{References}

1. Bruno V, Battaglia G, Copani A, D'Onofrio M, Di lorio P, De Blasi A, et al. Metabotropic glutamate receptor subtypes as targets for neuroprotective drugs. J Cereb Blood Flow Metab. 2001;21(9):1013-33.

2. Corti C, Battaglia G, Molinaro G, Riozzi B, Pittaluga A, Corsi M, et al. The use of knock-out mice unravels distinct roles for mGlu2 and mGlu3 metabotropic glutamate recptors in mechanisms of neurodegeneration/ neuroprotection. J Neurosci. 2007:27(31):8297-308.

3. Caraci F, Molinaro G, Battaglia G, Giuffrida ML, Riozzi B, Traficante A, et al. Targeting group II metabotropic glutamate ( $\mathrm{mGlu}$ ) receptors for the treatment of psychosis associated with Alzheimer's disease: selective activation of mGlu2 receptors amplifies beta-amyloid toxicity in cultured neurons, whereas dual activation of mGlu2 and mGlu3 receptors is neuroprotective. Mol Pharmacol. 2011;79(3):618-26.

4. Bruno V, Sureda FX, Storto M, Casabona G, Caruso A, Knopfel T, et al. The neuroprotective activity of group-II metabotropic glutamate receptors requires new protein synthesis and involves a glial-neuronal signaling. J Neurosci. 1997;17(6):1891-7.

5. Bruno V, Battaglia G, Casabona G, Copani A, Caciagli F, Nicoletti F. Neuroprotection by glial metabotropic glutamate receptors is mediated by transforming growth factor-beta. J Neurosci. 1998;18(23):9594-600.

6. Behrens MM, Strasser U, Heidinger V, Lobner D, Yu SP, McDonald JW, et al. Selective activation of group II mGluRs with LY354740 does not prevent neuronal excitotoxicity. Neuropharmacology. 1999;38(10):1621-30.

7. Bond A, O'Neill MJ, Hicks CA, Monn JA, Lodge D. Neuroprotective effects of a systemically active group II metabotropic glutamate receptor agonist LY354740 in a gerbil model of global ischaemia. Neuroreport. 1998;9(6):1191-3.

8. Bond A, Jones NM, Hicks CA, Whiffin GM, Ward MA, O'Neill MF, et al. Neuroprotective effects of LY379268, a selective mGlu2/3 receptor agonist: investigations into possible mechanism of action in vivo. J Pharmacol Exp Ther. 2000;294(3):800-9.

9. Cai Z, Xiao F, Fratkin JD, Rhodes PG. Protection of neonatal rat brain from hypoxic-ischemic injury by LY379268, a group II metabotropic glutamate receptor agonist. Neuroreport. 1999;10(18):3927-31.

10. Lam AG, Soriano MA, Monn JA, Schoepp DD, Lodge D, McCulloch J. Effects of the selective metabotropic glutamate agonist LY354740 in a rat model of permanent ischaemia. Neurosci Lett. 1998;254(2):121-3.

11. Yoshioka H, Sugita M, Kinouchi H. Neuroprotective effects of group II metabotropic glutamate receptor agonist DCG-IV on hippocampal neurons in transient forebrain ischemia. Neurosci Lett. 2009;461(3):266-70.

12. Motolese M, Mastroiacovo F, Cannella M, Bucci D, Gaglione A, Riozzi B, et al. Targeting type-2 metabotropic glutamate receptors to protect vulnerable hippocampal neurons against ischemic damage. Mol Brain. 2015;8(1):66.

13. Goeldner C, Ballard TM, Knoflach F, Wichmann J, Gatti S, Umbricht D. Cognitive impairment in major depression and the $\mathrm{mGlu2}$ receptor as a therapeutic target. Neuropharmacology. 2013;64:337-46.

14. Nygren J, Wieloch TJ. Enriched environment enhances recovery of motor function after focal ischemia in mice, and down regulates the transcription factor NGFI-A. Cereb Blood Flow Metab 2005;25(12):1625-1633.

15. Sharkey J, Ritchie IM, Kelly PA. Perivascular microapplication of endothelin-1: a new model of focal cerebral ischemia in the rat. J Cereb Blood Flow Metab 1993;13(5):865-71.

16. Ceolin L, Kantamneni S, Barker GR, Hanna L, Murray L, Warburton EC, et al. Study of novel selective mGlu2 agonist in the temporo-ammonic input to CA1 neurons reveals reduced $\mathrm{mGlu2}$ receptor expression in a Wistar substrain with an anxiety-like phenotype. J Neurosci. 2011;31(18):6721-31.

17. Wood CM, Nicolas CS, Choi SL, Roman E, Nylander I, Fernandez-Teruel A, et al. Prevalence and influence of cys $407^{*} \mathrm{Grm} 2$ mutation in Hannoverderived Wistar rats: mGlu2 receptor loss links to alcohol intake, risk taking and emotional behaviour. Neuropharmacology. 2017;115:128-38.

18. Schallert $T$, Upchurch $M$, Lobaugh N, Darrar SB. Tactile extinction: distinguishing between sensorimotor and motor asymmetries in rats with unilateral nigrostriatal damage. Pharmacol Biochem \& Behavior. 1982;16: 455-62.

19. Hardingham GE, Bading H. Synaptic versus extrasynaptic NMDA receptor signalling: implications for neurodegenerative disorders. Nat Rev Neurosci. 2010;11(10):682-96. 
20. Pellegrini-Giampietro DE. The distinct role of mGlu1 receptors in postischemic neuronal death. Trends Pharmacol Sci. 2003;24(9):461-70.

21. Bruno V, Caraci F, Copani A, Matrisciano F, Nicoletti F, Battaglia G. The impact of metabotropic glutamate receptors into active neurodegenerative processes: a "dark side" in the development of new symptomatic treatments for neurologic and psychiatric disorders. Neuropharmacology. 2017;15(115):180-92.

22. Gu Z, Cheng J, Zhong P, Qin L, Liu W, Yan Z. Aß selectively impairs mGluR7 modulation of NMDA signaling in basal forebrain cholinergic neurons: implication in Alzheimer's disease. J Neurosci. $2014 ; 8 ; 34(41): 13614-28$

23. Barth TM, Jones TA, Schallert T. Functional subdivisions of the rat somatic sensorimotor cortex. Behav Brain Res. 1990;39(1):73-95.

24. Grow JL, Liu YQ, Barks JD. Can lateralizing sensorimotor deficits be identified after neonatal cerebral hypoxia-ischemia in rats? Dev Neurosci. 2003;25(6):394-402.

25. Moscovitch M, Behrmann M. Coding of spatial information in the somatosensory system: evidence from patients with neglect following parietal lobe damage. J Cogn Neuroscience. 1994;6(2):151-5.

26. Aronowski J, Samways E, Strong R, Rhoades HM, Grotta JC. An alternative method for the quantitation of neuronal damage after experimental middle cerebral artery occlusion in rats: analysis of behavioral deficit. J Cereb Blood Flow Metab. 1996;16(4):705-13.

27. Watson GD, Smith JB, Alloway KD. Interhemispheric connections between the infralimbic and entorhinal cortices: the endopiriform nucleus has limbic connections that parallel the sensory and motor connections of the claustrum. Comp Neurol. 2017:525(6):1363-80.

28. Shi CJ, Cassell MD. Cascade projections from somatosensory cortex to the rat basolateral amygdala via the parietal insular cortex. J Comp Neurol. 1998;399(4):469-91.

29. Jasmin L, Rabkin SD, Granato A, Boudah A, Ohara PT. Analgesia and hyperalgesia from GABA-mediated modulation of the cerebral cortex. Nature. 2003;424(6946):316-20.

30. Pushparaj A, Kim AS, Musiol M, Zangen A, Daskalakis ZJ, Zack M, et al. Differential involvement of the Agranular vs granular insular cortex in the acquisition and performance of choice behavior in a rodent gambling task. Neuropsychopharmacology. 2015;40(12):2832-42.

31. Kosar E, Grill HJ, Norgren R. Gustatory cortex in the rat. I. Physiological properties and cytoarchitecture. Brain Res. 1986;379(2):329-41.

32. Yin J, Han P, Tang Z, Liu Q, Shi J. Sirtuin 3 mediates neuroprotection of ketones against ischemic stroke. J Cereb Blood Flow Metab. 2015;35(11):1783-9.

33. Paxinos $\mathrm{G}$, Watson $\mathrm{C}$. The rat brain in stereotaxic coordinates. Compact $3^{\text {rd }}$ ed. New York: Academic Press; 1998.

34. Moyanova S, Kirov R, Kortenska L. Multi-unit activity suppression and sensorimotor deficits after endothelin-1-induced middle cerebral artery occlusion in conscious rats. J Neurol Sci. 2003;212(1-2):59-67.

\section{Submit your next manuscript to BioMed Central and we will help you at every step:}

- We accept pre-submission inquiries

- Our selector tool helps you to find the most relevant journal

- We provide round the clock customer support

- Convenient online submission

- Thorough peer review

- Inclusion in PubMed and all major indexing services

- Maximum visibility for your research

Submit your manuscript at www.biomedcentral.com/submit

) Biomed Central 